\title{
INTERVENTIONISTISKE SKABELONER
}

Fotografisk iscenesættelse som dialogisk metode i antropologien

\author{
CHRISTIAN VIUM
}

I forskningsprojektet „Temporal Dialogues“ tager jeg udgangspunkt i fotografiske arkiver, fra hvilke jeg udvælger, printer og arrangerer billeder i notesbøger, som efterfølgende medbringes på etnografisk feltarbejde i de områder (det centrale Australien 2014, den brasilianske del af Amazonas 2015 samt Sibirien 2016), hvor de oprindeligt blev produceret mellem 100 og 150 år tidligere. Billederne anvendes $i$ dybdegående diskussioner og analyse af de originale fotografiers komposition, æstetik, betydning og kulturelle og historiske kontekst, såkaldt fotoelicitering (Buckley 2014; Edwards 2008). Et udvalg af arkivfotografierne fungerer som skabeloner for fotografiske rekonstruktioner (Agnew 2004; Collingwood 1946), der laves i samarbejde med lokale - ofte efterkommere af folkene, der er afbildet på arkivfotografierne, på de steder, hvor de oprindelige fotografier blev lavet. Disse iscenesatte rekonstruktioner sammenstilles til sidst med originalerne i montager (figur 1) samt skitser og tekst af forskellig art (feltnoter, akademiske citater, redigerede interviews, avisudklip og andre kilder) i en form for tværtemporale ansamlinger (Deleuze \& Guattari 1980) og tværkulturelle, kulturkritiske sammenstillinger (Marcus \& Fischer 1999). Disse præsenteres dels i artikel- og bogform, dels i form af tredimensionelle installationer og udstillinger. Jeg anvender således mine visuelle noter som skabeloner for praktiske fotografiske interventioner i produktionen af kvalitativ antropologisk viden i tæt samarbejde med mine informanter samt kollegaer og kuratorer. Denne interventionistiske metode faciliterer et særligt rum for dialog og analyse af det oprindelige fotografiske arkivmateriale. Den skaber desuden nye muligheder for en kulturkritisk behandling og rekontekstualisering af historiske dokumenter (Edwards 1992, 2001; Pinney \& Peterson 2003), der vægtlægger og fremhæver informanternes selvrepræsentation og analyse.

Nærværende projekt skriver sig således ind i en større postkolonial repræsentationsdebat (Bhabha 1994; Marcus \& Fischer 1999; Said 1978), der fortsat for- 
drer kritisk refleksion og kalder på nye demokratiske former for historieskrivning (McCalman \& Pickering 2010:11). Centralt i projektet er en eksperimenterende tilgang til forholdet mellem billede og tekst som komponenter i antropologisk forskning og formidling. I denne artikel søger jeg at sætte disse komponenter sammen på en måde, hvor læseren inviteres til selv at skabe sammenhænge - til at associere - på baggrund af sammenstillingerne, jeg præsenterer. Artiklen åbner med et uddrag fra en samtale i felten og diskuterer efterfølgende, hvorledes henholdsvis intervention og dialog udgør centrale elementer i projektet. Til slut argumenterer jeg for, hvorledes denne interventionistiske fotografiske iscenesættelse kan anskues som en ny antropologisk genre, der i praksis muliggør en kollaborativ metodisk og analytisk kulturkritik i grænselandet mellem socialvidenskabelige og billedkunstneriske tilgange.

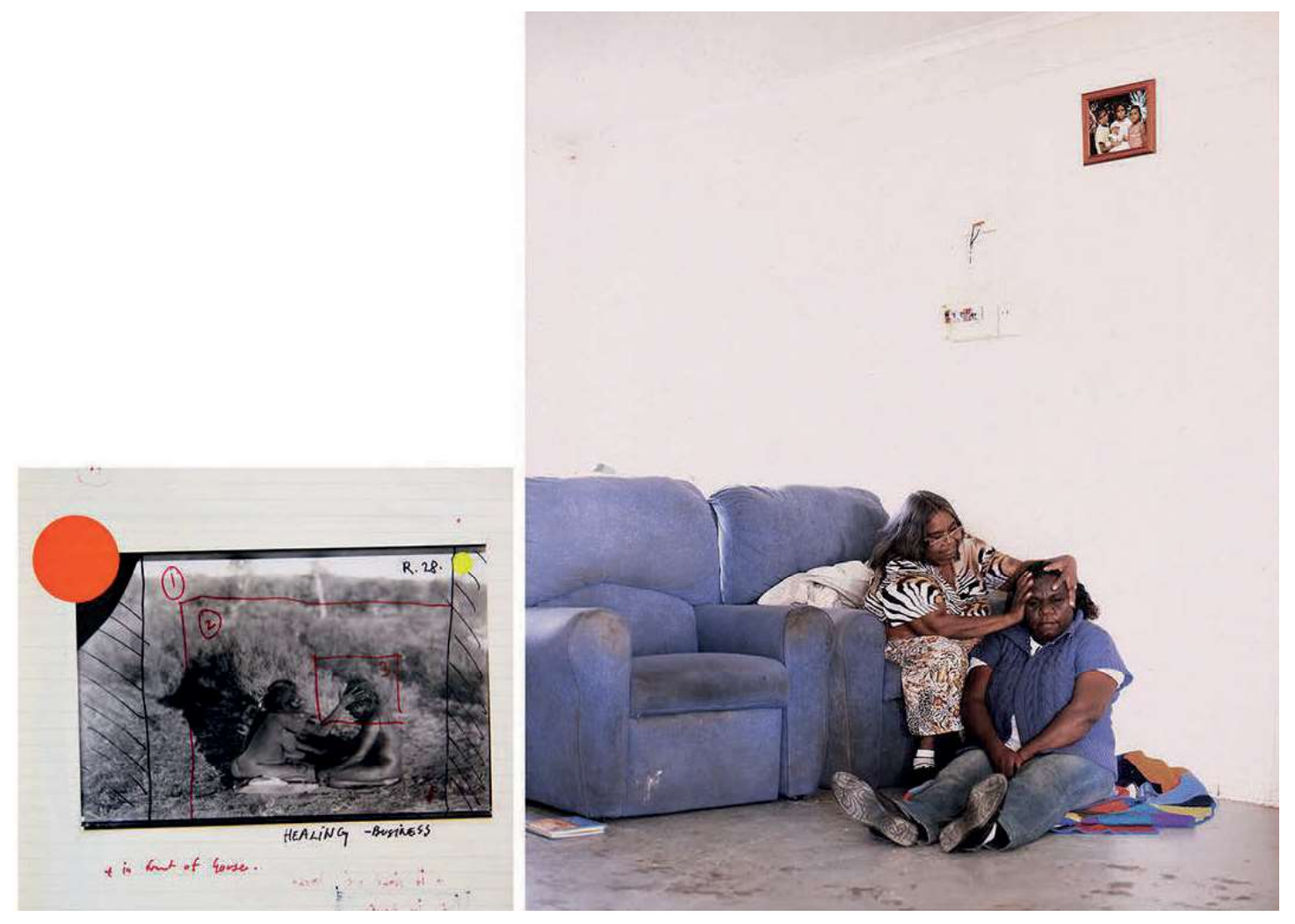

Figur 1.

\section{Uddrag}

Fra en samtale med Marie Ellis, en arandakvinde i midten af fyrrerne fra det centrale Australien, bosat i „bylejren“ Amoonguna uden for Alice Springs.

Tidlig eftermiddag. Vi sad på plastikstole i skyggen uden for Marie og Scottys hus, den gamle butikbestyrers hus, hvis vindue var prydet af ordene „Fuck You“" På den tilstødende nabos metalhegn havde nogen skrevet ,Fuck this place is shit“. 
Længere nede af Gum Tree Road var en bil kollideret frontalt med et træ, da føreren havde været på druk i weekenden. Dækkene var væk. Marie smilede og var i sit sædvanlige sarkastiske humør.

Vi var i gang med at gennemgå et udvalg af Spencer og Gillens fotografier af aranda- og warlpirikvinder. Hovedsageligt portrætter, men også billeder af såkaldt „,sorry business“: ceremonier, ritualer og praksis omhandlende sorg. Det var især sidstnævnte fotografier, der havde påkaldt sig min opmærksomhed under min gennemgang af Spencer og Gillens omfattende arkiver. Disse billeder var mindre statiske, mere ambivalente og åbne for fortolkning end de andre billeder $i$ arkivet - og end de fleste etnografiske og koloniale fotografier frembragt i den samme periode (mellem 1870 og 1910).

Som jeg havde bemærket tidligere, når kvinder gennemgik fotografierne, var berøringen en vigtig del af ,læsningen“ af billederne. Det var ikke nok blot at se på billederne. For at kunne begribe og sanse billedernes sprog måtte man engagere sig i deres materialitet, og denne fysiske kontakt syntes at fremkalde mere detaljerede og affektive beskrivelse og refleksioner. Marie bladrede igennem albummet af skitser, som jeg havde sammensat med henblik på de senere fotografiske dramatiseringer og genskabelser. Et efter et læste hun billederne og tilbød sin fortolkning, sine refleksioner, sin viden og sine holdninger. Vores samtale bevægede sig ofte ad uventede veje. Diskussioner om temaer, der var forbundet til den fortsatte kløft mellem de oprindelige og hvide australiere, kunne udspringe af en hånds gestik eller en blikretning i de gamle fotografier, vi sammen betragtede. Lidt inde i vores samtale nåede vi til et fotografi af en korthåret kvinde, der stirrede nedad (figur 2), og efter et øjebliks stille kontemplation tilbød Marie følgende fortolkning:

Hendes blik er ... hun skærer ansigt, ved du. Eller tænker. Hun tænker måske ligesom 'Jeg vil ikke være her. Jeg vil ikke fortælles, hvad jeg skal gøre ... det her pisser mig af. Jeg kan ikke lide det.' Faktisk tænker hun sandsynligvis 'fuck off!'

Maries reaktion var repræsentativ for mange af mine informanters tolkninger af de oprindelige fotografier af deres forfædre. Men den kritiske analyse af det kulturmøde, der lå til grund for fotografierne og det udtalt ulige magtforhold mellem bosættere (settlers) og oprindelige australiere (aboriginere), gik som oftest hånd $i$ hånd med en værdsættelse af fotografiernes affektive kvaliteter og deres betydning for erindring og bevarelse af de oprindelige australieres historie og kulturarv (jf. Edwards et al. 1992; Lydon 2014). Denne dobbelthed eller ambivalens løber som en ledetråd gennem mit projekt, hvilket jeg håber at vise. 


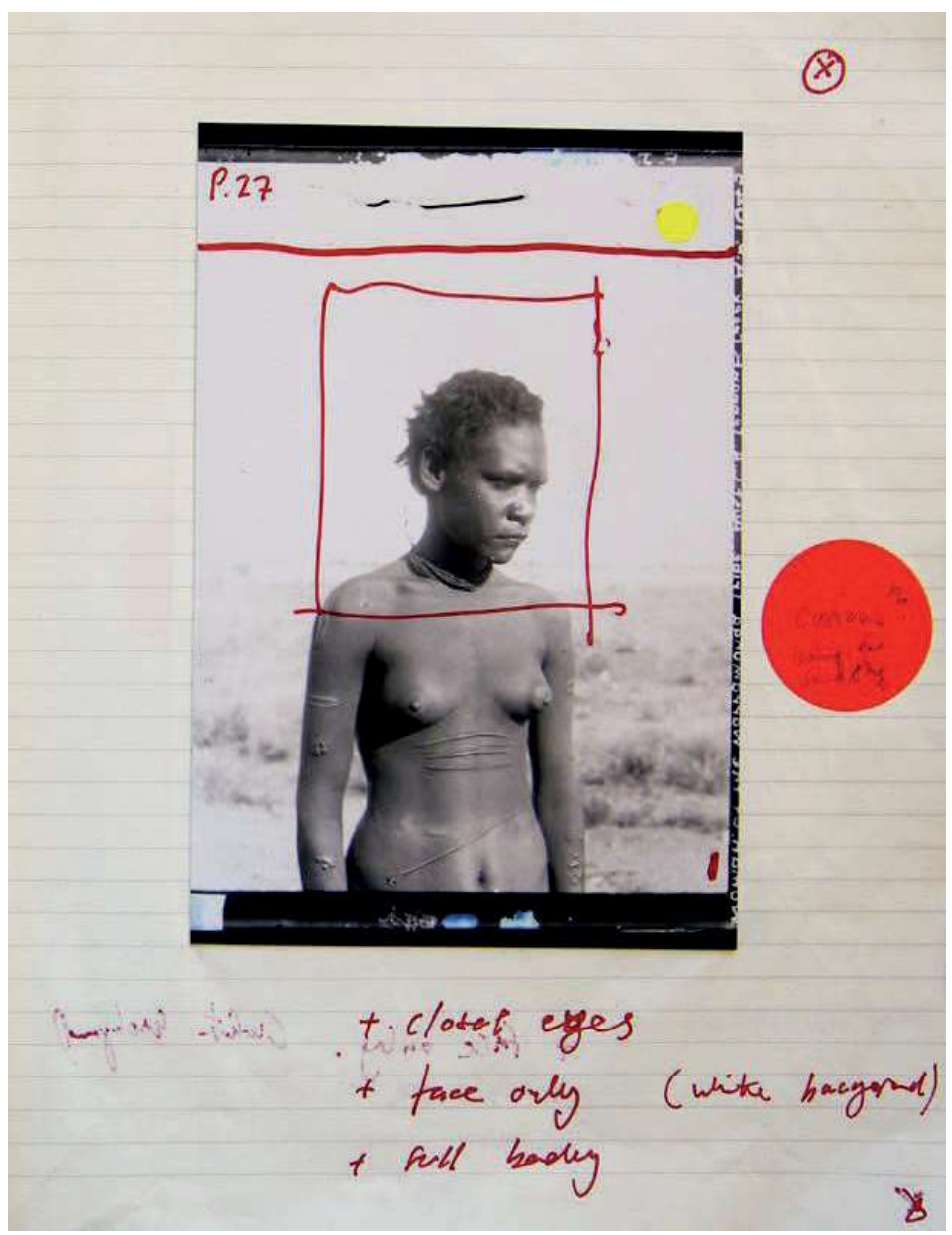

Figur 2.

\section{Intention}

I maj og juni 2014 arbejdede jeg i det centrale Australien på at iscenesætte en række af sir Baldwin Spencer og Frank J. Gillens banebrydende fotografiske arbejder. Over fire årtier mellem 1875 og 1912 producerede Spencer og Gillen omfattende og særdeles indflydelsesrige optegnelser over den oprindelige australske befolknings hverdag og ritualer. Årtier før Bronislaw Malinowskis berømte deltagerobservationer i Stillehavet prioriterede og praktiserede Spencer og Gillen dybdegående og langvarige feltarbejder baseret på deltagerobservation samt brugen af fotografi og film som en integreret del af deres metode. Deres arbejde fik stor indflydelse på socialvidenskaberne (Mulvaney et al 1997; Vium under udgivelse a og b). Min hensigt var at bruge deres arbejde som grundlag for en nutidig dialog om antropologiens anskuelse og repræsentation af kulturel andethed. De originale fotografier fungerede som materielle og metodiske katalysatorer for en detaljeret fotoelicitering og for samtaler og interviews i felten samt den efterfølgende produktion af nye fotografier på baggrund af de originale. Det 
blev en praktisk metode til at interagere og samarbejde med mine informanter. Mit ønske var at invitere mine informanter ind i et performativt og kollaborativt rum, i hvilket de blev ansporet til at arbejde med deres selvrepræsentation i direkte dialog med de gamle fotografier af deres forfædre og deres land. Min forventning og forhåbning var, at denne form for praktisk samarbejde omkring iscenesættelsen af nye fotografier på baggrund af fotoelicitering (Buckley 2014; Richard et al. 2015) ville skabe en form for konstruktiv fremmedgørelse eller Verfremdung (Brecht 1964), der kunne destabilisere forudindtagede antagelser om, hvad både de oprindelige og vores nye billeder egentlig repræsenterer. I stedet for blot at samtale om fotografierne forestillede jeg mig, at de oprindelige australiere ville opleve en ganske anderledes form for refleksion og erkendelse, når de blev opfordret til at eksperimentere med repræsentationen af sig selv og deres forfædre. Formodningen var, at det ville ske i kraft af den kropslige indlejring af kulturkritisk viden, som jeg håbede, dette eksperiment ville afstedkomme.

Til grund for mit projekt lå der altså fra starten en forventning om, at vi sammen gennem den proces, jeg havde planlagt - fra mit indledende arkivarbejde over fotoelicitering og samtalerne, de deraf følgende fotografiske iscenesættelser af det originale materiale samt siden hen min bearbejdning og endelige tredimensionelle udstilling af arbejdet - ville bevæge os igennem en form for kulturkritisk gennemarbejdning af den tunge koloniale arv og dens fortsatte indvirkning i nutidens Australien. Således skriver projektet sig ind i en efterhånden veletableret kritisk australsk (visuel) antropologi, der gennem participatoriske og ofte aktivistiske tilgange søger at rekontekstualisere og debattere bosættelses- og koloniseringspraksis ved at inddrage oprindelige australieres oplevelser, analyser og holdninger i de faglige diskussioner (Deger 2006, 2013, 2016; Ginsburg 1995, 2012; Michaels 1993; Lydon 2012, 2014).

\section{Intervention}

Da jeg først præsenterede min idé om at nyfortolke Spencer og Gillens fotografier sammen med mine informanter, brugte jeg betegnelsen intervention. Denne betegnelse anvendes ofte inden for kunstverdenen og i stigende grad inden for den eksperimenterende gren af nyere antropologi (Schneider 2010; Schneider \& Wright 2013). Jeg ønskede at begrebsliggøre min tilgang til dette specifikke forskningsarbejde. Betegnelsen intervention italesætter det forhold, at kunstneren såvel som antropologen aktivt blander sig og påvirker den situation eller det felt, denne intervenerer i på baggrund af mere eller mindre improviserede teknikker og forestillinger. Der er med andre ord tale om en bevidst strategi for at operere inden for en given felt på baggrund af en erkendelse af egen positionering og 
indflydelse. Modsat den bedagede idé om den neutrale, observerende antropolog, der minimerer sin påvirkning af felten (hvad man inden for dokumentarfilmen ofte omtaler som „fluen på væggen“), ønskede jeg netop at arbejde med iscenesættelsen som fordring og udgangspunkt snarere end som et negativt element, der skulle undgås eller minimeres - endsige maskeres - ved hjælp af diverse retoriske teknikker og strategier.

Som antropolog, fotograf og filmskaber forekommer tanken om at være en slags flue på væggen mig ikke alene konservativ, men også for abstrakt. Derfor bliver det relevante spørgsmål, i hvilket omfang man ønsker at omfavne det grundvilkår, at man ved sin tilstedeværelse påvirker felten, og arbejde med det som et produktivt benspænd. At intervenere, instruere, dramatisere og påvirke sin felt kan ses som analytiske handlinger, der medvirker til at skabe felten og den viden, der siden formidles herom. Her ser jeg ikke den store forskel fra at foretage et struktureret eller delvist struktureret interview, der er indrammet af en række spørgsmål, som tjener det formål at belyse specifikke aspekter af et givent tema eller en afgrænset problemstilling. I forlængelse heraf opfatter jeg heller ikke den store forskel mellem på den ene side det at redigere et interview og sammenskrive feltnoter og på den anden side det at efterredigere, beskære og sætte udvalgte fotografier i sammenhæng med hinanden. De færreste antropologer vil vel argumentere for, at man skulle publicere hele det transskriberede interview uredigeret frem for at udvælge analytisk relevante passager. Hvor ville den antropologiske analyse så befinde sig? 


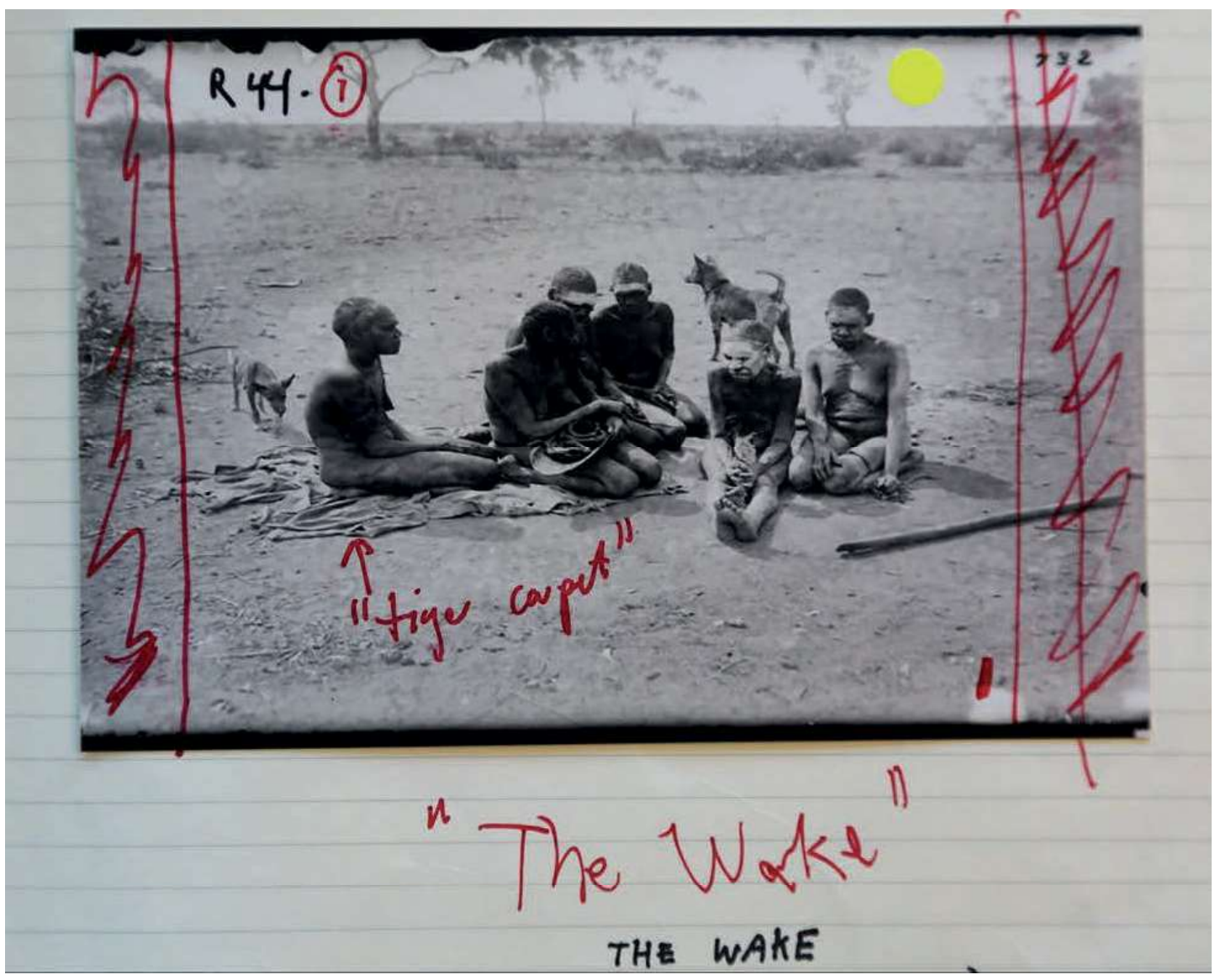

Figur 3.

\section{Dialog}

Når mine informanter inviteres til at diskutere de oprindelige fotografier og efterfølgende iscenesætte og nyfortolke dem sammen med mig, skaber vi et særligt rum for en praktisk dialog centreret om vores associationer. Sammen associerer vi på baggrund af de oprindelige billeder i samspil med det faktiske sted, vi befinder os, og skaber nye billeder, der taler til de oprindelige og vice versa. I denne proces oplevede jeg ofte, hvordan kvinderne og mændene foran kameraet blev særligt påvirkede følelsesmæssigt. Det, at de mimer (jf. Taussig 1993:46) og dermed kropsliggør de oprindelige fotografier ved helt bogstaveligt at sætte sig selv i deres forfædres position gennem kropslig kopiering, synes at intensivere deres affektive refleksioner over indholdet og konteksten for de originale fotografier. I det følgende vil jeg give et kort eksempel på denne kropsliggjorte form for refleksiv kulturkritik. Sammen med en gruppe kvinder fra Amoonguna, en såkaldt town camp uden for Alice Springs, som jeg havde talt med om Spencer og Gillens fotografier ved flere forudgående lejligheder, havde vi aftalt at lave en fotografisk iscenesættelse af en håndfuld billeder (heriblandt figur 3), der alle 
kredsede om temaet „,sorry business“, der helt konkret relaterer sig til ritualiserede former for sorgbearbejdelse blandt oprindelige australiere (Musharbash 2008; Glaskin et al. 2008). Kvinderne Nola, Lynette, Roseanne og Marie var alle dybt koncentrerede og alvorlige, da vi begyndte iscenesættelsen, og inden der var gået et par minutter, undskyldte de sig alle og gik hver især til deres huse, hvorfra de vendte tilbage et kvarter senere. De havde skiftet tøj og bar nu alle sorte T-shirts og lange nederdele. Stemningen var fortsat dybt koncentreret, og sammen skabte vi nu en række individuelle portrætter og gruppeportrætter, alle med reference til de oprindelige fotografier. På trods af at vores verbale dialog var begrænset til nogle få udvekslinger omkring positurer, blikretninger og ideer til opstillinger, fremgik det tydeligt, at kvinderne befandt sig et refleksivt rum, hvor de oversatte deres følelser kropsligt og fremstillede dem i deres positurer foran kameraet (se figur 4).

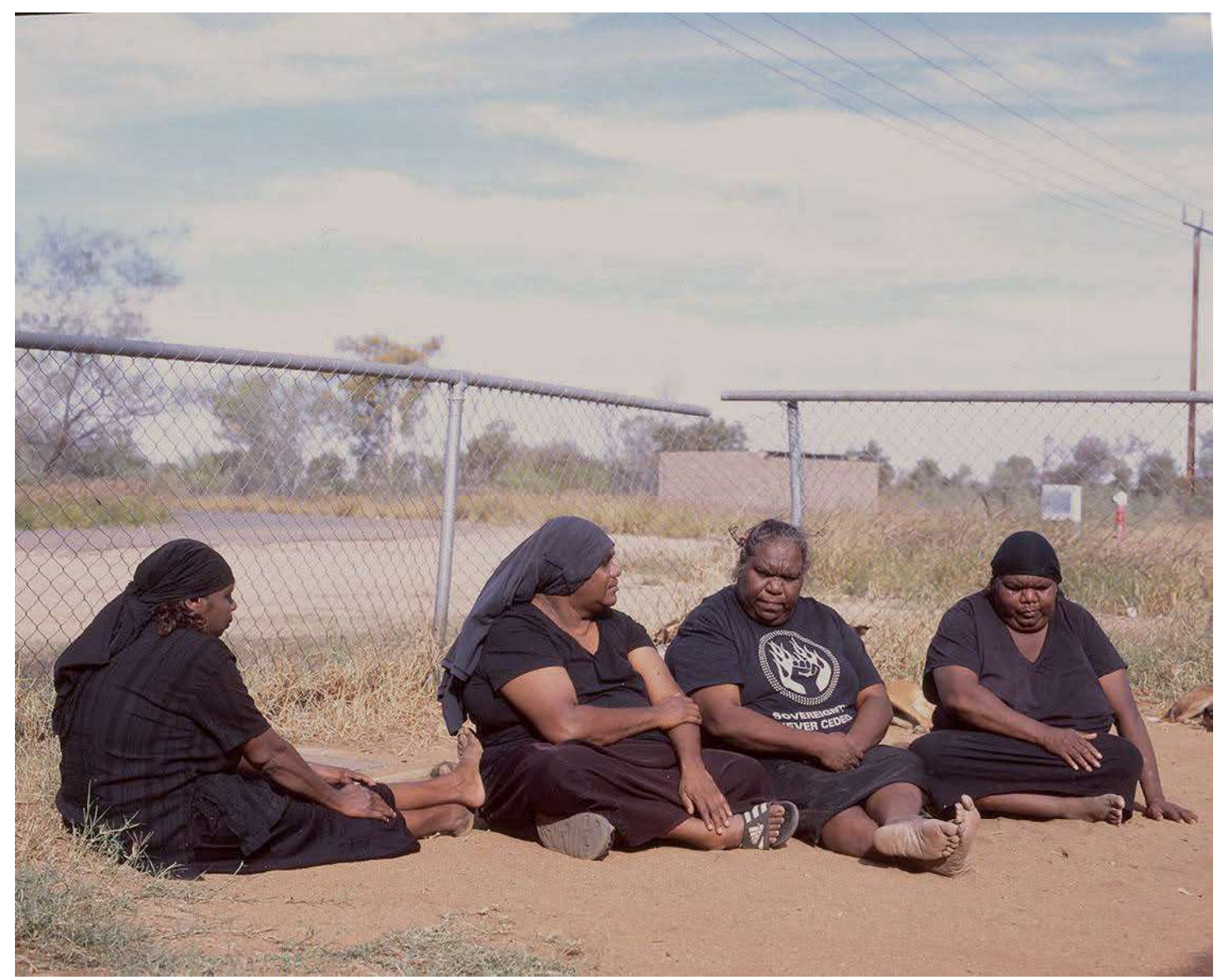

Figur 4. 
En måde at begrebsliggøre dele af denne på sin vis terapeutiske proces på er gennem en diskussion af begrebet anamnese (genkaldelse, ihukommelse eller erindring), som fænomenet beskrives af Jean-Francois Lyotard (2004) med reference til Sigmund Freuds kliniske begreb Durcharbeitung (gennemarbejdelse). Anamnese udforsker nutiden gennem såkaldt frie associationer til historien. Modsat mere konventionelle videnskabelige tilgange, der lægger vægt på argumentationen, drejer anamnese sig ifølge Lyotard ikke om at undersøge fortiden for at etablere sandheden om historien, men om at gennemarbejde en nuværende situation og de faser fra historien, der associeres med den, for derigennem at opnå en mere nuanceret erkendelse. For mine informanter kom en sådan erkendelse både til udtryk i forbindelse med fotoeliciteringen, den fotografiske iscenesættelse og de efterfølgende diskussioner. Begrebet Durcharbeitung er relevant, fordi det lægger vægt på det processuelle i gennemarbejdninger af historiske traumer, der indvirker på individets væren i nutiden.

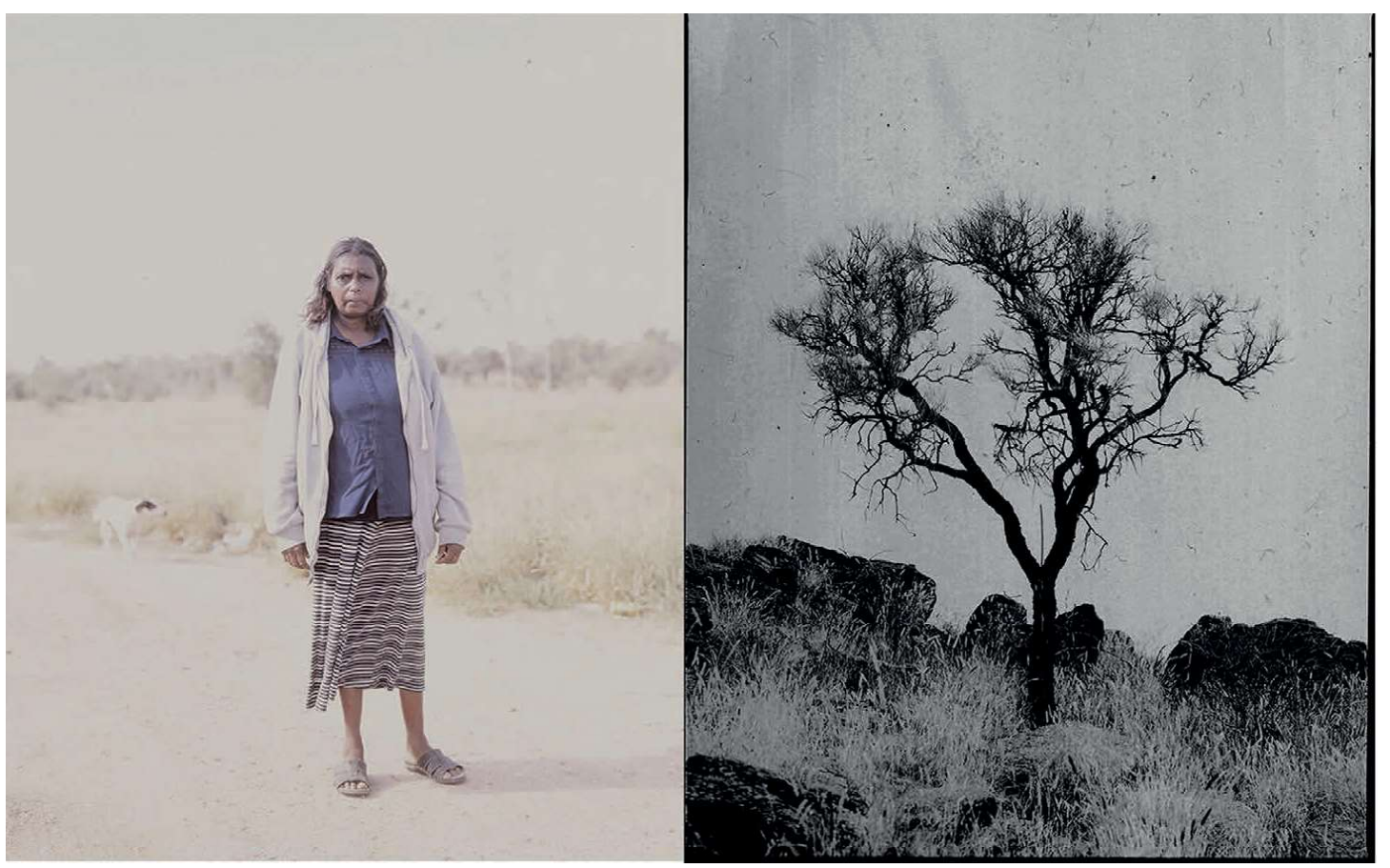

Figur 5.

\section{Iscenesættelse}

Med reference til blandt andre den franske etnograf og filmskaber Jean Rouch, der proklamerede at ,... kameraet deformerer ... men ikke fra det øjeblik, hvor det bliver en medvirkende. På det tidspunkt har det [kameraet] muligheden for at gøre noget, jeg ikke kunne gøre, hvis kameraet ikke var der. Det bliver en slags psykoanalytisk stimulans, der lader folk gøre ting, de ellers ikke ville gøre" 
(Rouch i Renov 2004:127). Jeg oplevede et stærkt element af følelsesmæssig intensivering i denne proces, og det indvirkede på den form, vores fotografiske iscenesættelser antog. De er ikke minutiøst planlagte og detaljerede en-til-enreproduktioner af de originale billeder, men kan snarere begribes som en form for delvist improviserede og fleksible koreografier, der udspiller sig inden for et enkelt og relativt løst rammeværk eller dialogisk rum omkring et tema. Vores samarbejde bliver en løst struktureret leg, hvori alle deltagere eksperimenterer sammen gennem individuelle og kollektive associationer. Dem, der er foran kameraet, afprøver og introducerer løbende nye positurer. De elaborerer de originale fotografier, samtidig med at jeg bag kameraet løbende intervenerer: justerer eller dirigerer forløbet ved at tale, kommentere eller bede de medvirkende om at afprøve et andet blik eller en ny kompositorisk formation. På den måde leger vi os frem inden for en åben associerende form, hele tiden med kameraet som en aktiv deltager i processen.

Et af mine motiver for at arbejde med en åben og delvis improviseret metodologisk tilgang under de nye iscenesættelser af de originale fotografier var et ønske om at undersøge, hvorvidt det problematiske forhold mellem realisme, autenticitet og effekt bliver mere åbenlyst, når grænserne for genskabelse eller mimesis (Gebauer \& Wulf 1992; Taussig 1993) skubbes mod improvisationen som foreslået af McCalman og Pickering (2010:9). På samme måde som den tyske filminstruktør Werner Herzog, der understreger, hvorledes han opfinder med henblik på at opnå en dybere indsigt (Prager 2007:8), oplevede jeg, at mine informanter og jeg på sin vis opfandt en ny form for poetisk eller allegorisk virkelighed igennem disse iscenesatte fotografiske genskabelser.

De delvist improviserede genskabelser foregik dels i grupper, dels én til én, alt afhængigt af de originale billeder og den kontekst, vi arbejdede i. Ofte startede sessionerne med en kort samtale efterfulgt af nogle mere uformelle indledende fotografier for at etablere en afslappet om end fokuseret stemning. Nogle gange havde jeg allerede orienteret mig i området og noteret mig steder, vi kunne fotografere, der korresponderede med de originale billeder eller indeholdt informationer, jeg forestillede mig kunne bidrage med noget interessant $\mathrm{i}$ billederne. Ofte var det mine informanter selv, der foreslog steder og kom med ideer til, hvilke af de originale fotografier vi skulle bearbejde sammen og hvordan. Således opstod der en dynamisk dialog, som fik plads til at udvikle sig løbende, men altid med øje for de mere overordnede pejlemærker i projektet. Vores arbejde kom til at fremstå som en art stiliserede øjeblikke, hvori vi konstant blev mindet om, at vi sammen skabte sammenhænge og kropsliggjorde spørgsmål, der sprang ud af vores diskussioner og læsninger af de oprindelige fotografier i samspil med de umiddelbare omgivelser, sociale som økologiske, vi arbejdede i. For at demon- 
strere vores samarbejde følger her en præsentation og diskussion af et par af de mange fotografiske seancer, vi sammen gennemgik under mit feltarbejde i det centrale Australien.

Blandt de hundredvis af fotografier, jeg konsulterede i min gennemgang af Spencer og Gillens samling, var der et betragteligt antal portrætter. Ofte enkle og typologiske i deres registrerende komposition med en eller flere personer vendt direkte mod kameraet. På trods af den næsten stringente formalitet i kompositionen syntes der at være en næsten mystisk kritik indlejret i disse gamle glasplader med afbildninger af for længst afdøde mennesker, hvis blikke mødte en. Mine informanter og jeg delte en oplevelse af en dybt forankret dobbelthed mellem stolthed og sorg, og hvad vi tolkede som en grundlæggende skepsis over for fotografen (og underforstået den hvide mand som sådan) og dennes teknologiske protese, kameraet. Det var en skepsis, jeg selv mødte under mit fotografiske feltarbejde i det centrale Australien. En sund skepsis, der i mine øjne er særdeles produktiv, da den fordrer en dialog og afkræver, at jeg gør mine intentioner klare over for de mennesker, jeg ønsker at arbejde sammen med og portrættere. Hvorfor er jeg overhovedet kommet? Hvad er min ambition? Hvilket formål tjener mit arbejde, og hvem er det rettet imod? Hvad er min egentlige berettigelse for at henvende mig og bede om et billede, en holdning, et svar på et givent spørgsmål? Alle disse fundamentale spørgsmål stilles på spidsen, i det øjeblik det drejer sig om at fotografere.

Der ligger en nærmest uhyggelig magt i fotografiet som repræsentation, men også et enormt potentiale for kulturkritisk samarbejde. Samtidig er fotografiet konkret. Det er et billede på noget, en fastfrysning af et øjeblik, en situation. En fremstilling, der bevares for eftertiden. Men således også abstrakt, i og med at det fragmenterer tidens flygtighed og standser tiden ganske bogstaveligt (Vium 2014). Gennem fotografiet er det muligt at erfare verden radikalt anderledes end uden og, som den ovenstående beskrivelse af vores fotografiske iscenesættelser vidner om, skabe verden på ny gennem eksempelvis transtemporale sammenstillinger eller montager, der stiller spørgsmålstegn ved ideen om lineær tid og historisk kausalitet samt ideen om repræsentation som værende en magt, der alene er reserveret den, der opererer kameraet. 


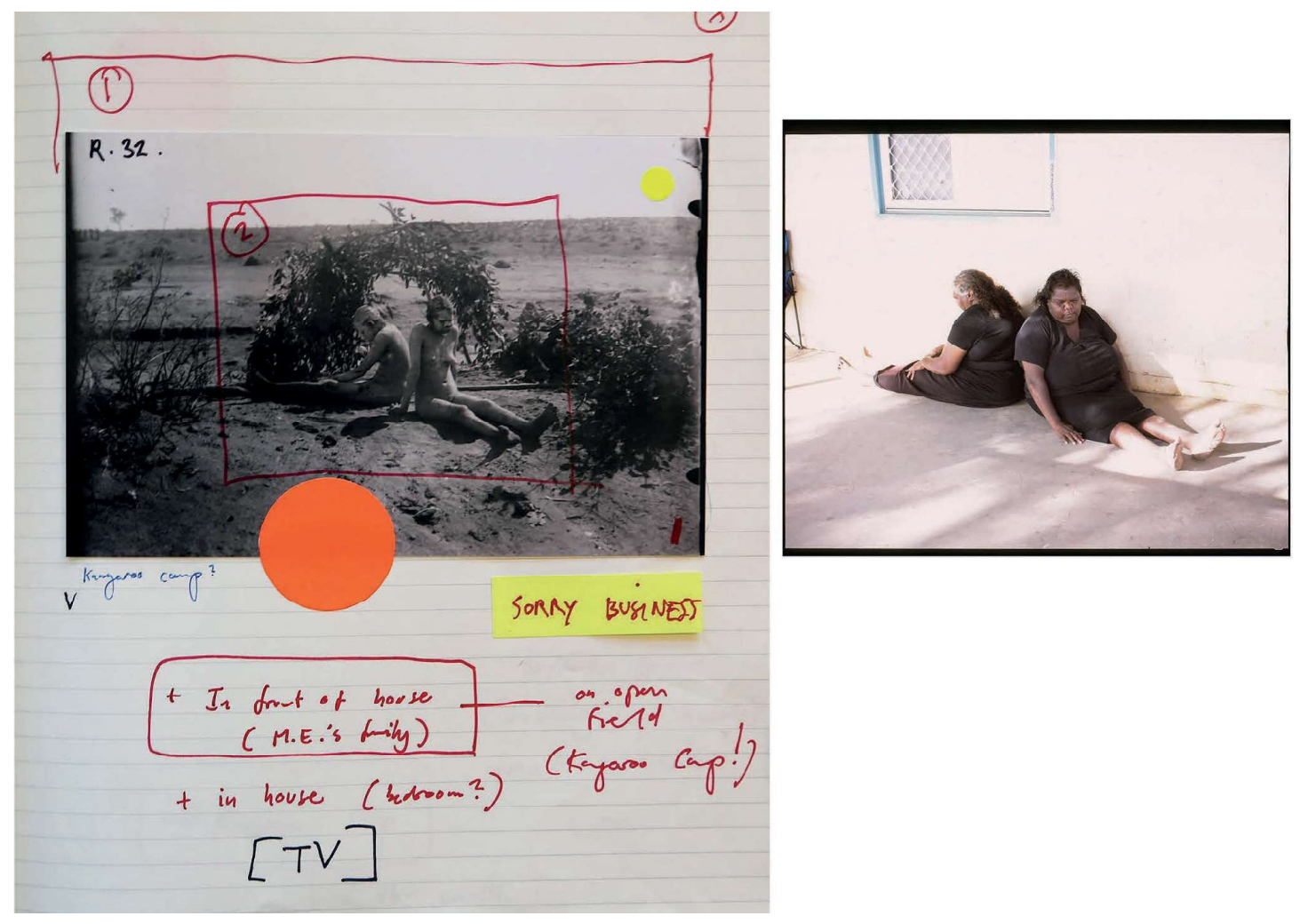

Figur 6.

\section{Analyse}

Hvor de gamle fotografier i høj graf fremstod typologiske, kan vores nye portrætter måske bedst klassificeres under Bill Nichols termer brechtiansk distancering og stilisering. Hvor det førstnævnte står for en afstandstagen fra realistiske repræsentationer gennem sociale gesturer, der tillader ,en stærkere forbindelse til historisk specificitet at komme i spil gennem filmmagerens [eller i dette tilfælde antropologen bag kameraet og informanterne foran kameraets] beslutning om at gestikulere til det historiske snarere end at repræsentere det illusionistisk" (Nichols 2008:85). Stilisering suspenderer betragteren i ,betydningsdannere, der besidder en ikonisk frem for en indeksikal relation til, hvad der allerede er sket" (op.cit.86). Dette knytter an til ideen om Durcharbeitung, som jeg tidligere har introduceret, samt til Lyotards opfordring til at give fortiden en konkret tid og et konkret rum, igennem hvilke beslutningen om at erindre og udrede ens trauma ledes tilbage til chokket gennem anamnese. Et relevant eksempel på en sådan brug af Durcharbeitung er Lanzmanns monumentale holocaustprojekt Shoah (1985) og Joshua Oppenheimers nylige diptykon The Act of Killing (2012) og The Look of Silence (2014), der undersøger det indonesiske folkemord på kommunister i 1960'erne på en yderst bemærkelsesværdig måde gennem netop retraumatise- 
ringsstrategier. Sidstnævnte film er efter min opfattelse et kulturkritisk postkolonialt manifest, der understreger, at det at erindre er ,en sammensætning af den splittede fortid for at skabe mening i nutidens traume" (Bhabha 1994:3). I The Location of Culture beskriver Homi Bhabha det, han kalder et liminalt identifikationsøjeblik, hvilket producerer en form for „,subversiv strategi for subaltern handling“" (op.cit.185). Han argumenterer således: „Magten i den postkoloniale oversættelse af moderniteten hviler i dens performative, deformative struktur, som ikke bare genvurderer indholdet af en kulturel tradition eller flytter værdier 'tværkulturelt'. [...] Det er for at introducere en anden inskriptionslocus og intervention, et andet hybridt, 'upassende' udsigelsessted gennem denne temporale kløft - eller tidsforskydning - at jeg har åbnet op [...] for betydningen af postkolonial agens" (Bhabha 1994:241-42, originale fremhævelser).

Dette leder mig videre til den tyske filminstruktør Werner Herzog, der ligeledes har arbejdet med genskabelser og Verfremdung som et greb i flere af sine film. Herzogs stilistiske og allegoriske tilgang til det at skabe filmkunst og historiefortælling er i mine øjne nært beslægtet med tænkere som Brecht, Debord, Schlovsky og Taussig. Ligesom dem stiller Herzog grundlæggende spørgsmålstegn ved ideen om det virkelige og er citeret for en nietzcheansk tilgang: „Jeg opfinder, men jeg opfinder med henblik på at opnå en dybere indsigt" (Prager 2007: 8, med reference til Davis 2006). Han henviser til at „,der er noget sådant som en poetisk, ekstatisk sandhed... [den] er mystisk og flygtig og kan kun nås gennem fabrikation, forestilling og stilisering“" (Cronin 2002:301). Herzog er således inspirerende for mig som antropolog, der arbejder med og gennem billeder, fordi han stiller spørgsmålstegn ved og undersøger virkeligheden gennem kunsten.

Herzogs betegnelse ekstatisk sandhed slår mig som værende rammende i sin begrebsliggørelse af et egentligt poetisk rammeværk for det at engagere sig i de surreelle - eller hyperreelle - øjeblikke af klarhed, der opstår lejlighedsvis, når man arbejder med mennesker og billeder, stillestående eller i bevægelse. Ifølge Herzog er evnen til at transfigurere virkeligheden det, der adskiller poeter fra bogholdere, og det er netop derfor, han så overbevisende advokerer for at stilisere i sine værker: Som Brecht ønsker han, at publikum tvinges til at reflektere over det faktum, at det, de betragter, er en kunstners eller en andens kreation og ikke rå ubearbejdet virkelighed (Prager 2007:14). En sådan kunstnerisk og poetisk tilgang tilbyder en række muligheder for antropologisk kulturkritik.

Jeg vil i det følgende konkludere min analyse ved at vende mig mod de to afgørende begreber sammenstilling (juxtaposition) og defamiliarisering (defamiliarization), således som de er præsenteret af Marcus og Fischer (1999). Ved konkret og praktisk at gennemarbejde ved hjælp af fotoelicitering og fotografisk iscenesættelse undersøger jeg de sprækker, der opstår mellem fortid og nutid, 
vel vidende at jeg er dømt til at fejle, $i$ den forstand at det ikke er muligt at skabe en-til-en-repræsentationer af de originale repræsentationer, men at denne umulighed netop er potentialet. Der er altid en høj grad af uforudsigelighed, og det er netop i anerkendelsen af denne, at en kreativ rekontekstualisering af fortiden bliver mulig (McCalman \& Pickering 2010:13). Det er netop, fordi det ikke lykkes, at nye indsigter opstår. Fordi det føles forkert eller ved siden af - i min tolkning fremmedgørende - at vi (jeg, mine samarbejdspartnere i felten og publikum) bliver klar over de detaljer og omstændigheder, der præger og betinger ikke blot de originale fotografer, men også vores nye, kollaborative fotografier. Som Vanessa Agnew pointerer, er den frigørende gestus ved den genskabelse (re-enactment), der er en omskabelse, at den tillader deltagerne at vælge deres egen fortid i reaktion på en konfliktfyldt nutid. Paradoksalt nok er det genskabelsens ahistoricitet, der udgør grundlaget for det kritiske engagement i det historiske materiale (Agnew 2004:328). Afstanden mellem virkelighed og repræsentation understreges, og anakronismen bliver et afgørende praktiske redskab i menings- og affektdannelsen. Således fremstår epistemologisk kritik og tværkulturel sammenstilling som ,varianter over en grundlæggende kritisk defamiliariseringsstrategi“ (Marcus \& Fischer 1999:137). Her bliver de til centrale metodologiske og analytiske redskaber i dette kombinerede forsknings- og udstillingsprojekt. Hverken jeg eller mine informanter oplevede Spencer og Gillens fotografiske repræsentationer af den oprindelige australske kultur som udtryk for en syntese. Jeg ønskede, at de endelige montager, jeg producerede på baggrund af vores arbejde, skulle fremstå synkretiske og fragmenterede, da jeg finder, at dette bedst repræsenterer den opbrudte montage af de lag oven på lag af erindringer, meninger, handlinger, diskurser og følelser, vi navigerede i. 


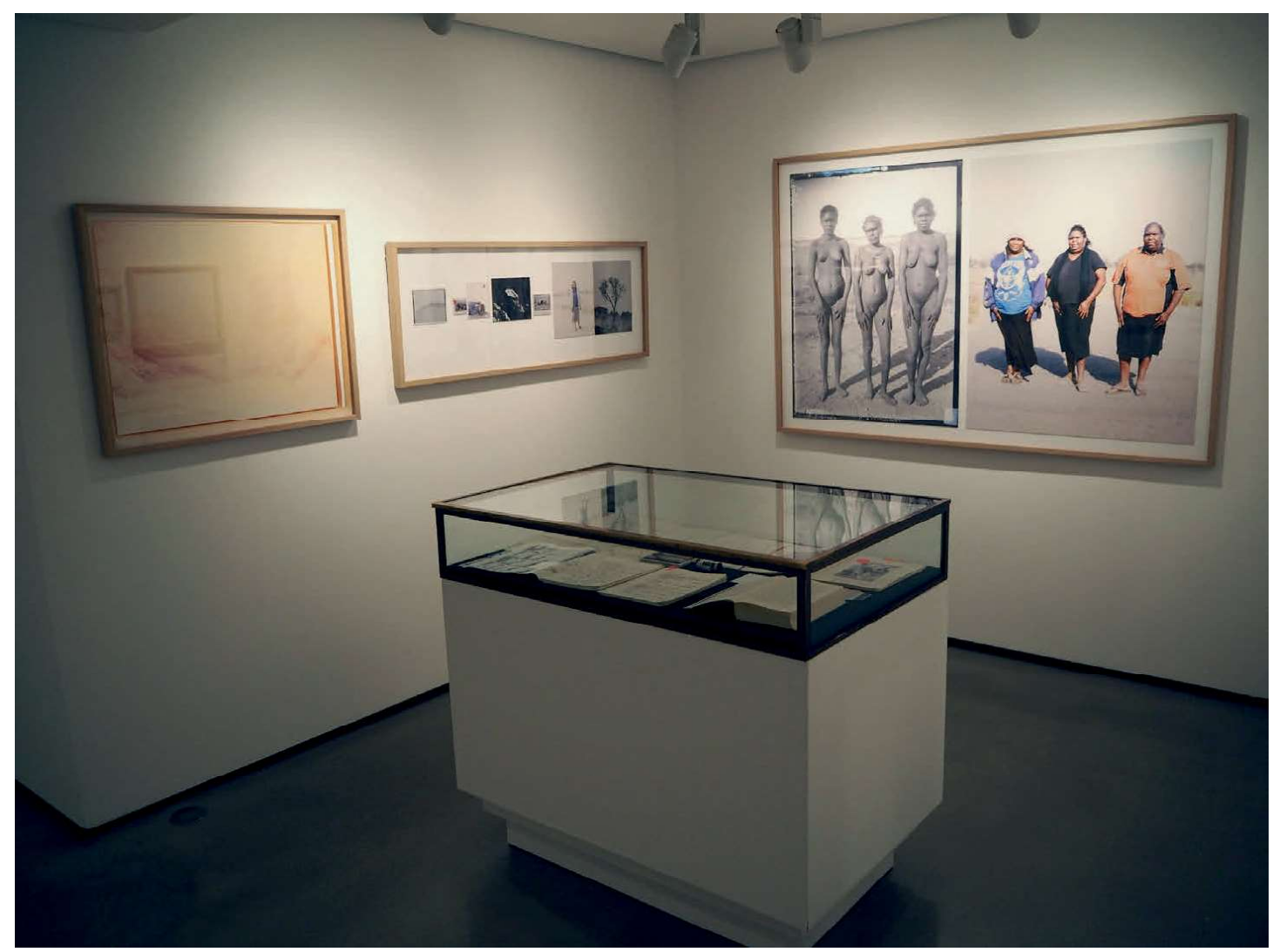

Figur 7.

\section{Montage}

Et udvalg af materialet, som jeg producerede sammen med mine informanter i det centrale Australien, er siden efteråret 2015 blevet præsenteret i mere end ti udstillinger i ni lande og udgivet i blandt andet Frankrigs største avis Le Monde samt det toneangivende fotografiske tidsskrift FOAM Magazine. Udstillingerne tog form af en række montager af mine fotografier og Spencer og Gillens originale fotografier samt tekstfragmenter, notesbøger og objekter, herunder et udvalg af mine negativer og testprint samt en videoinstallation, jeg producerede. Udstillingerne var et vigtigt element i mit analytiske arbejde, da det tillod mig at gennemtænke materialet på en anderledes måde end gennem den mere konventionelle videnskabelige produktion af tekst. Jeg redigerede billedmaterialet og konceptualiserede tredimensionaliseringen af materialet, som blev effektueret i samarbejde med kuratorer, der var tilknyttet de forskellige udstillingssteder. Selve redigeringen foregik i forskningsprojektet Camera as Cultural Critiques forskningslaboratorium på Moesgaard Museum i Aarhus og involverede telefoniske og onlinediskussioner med nogle af de informanter, jeg arbejdede sammen med og portrætterede under mit feltarbejde i Australien. Oprindeligt havde jeg øn- 
sket, at denne udvælgelse kunne foregå i Australien, men mit forskningsbudget tillod mig ikke at gøre dette, hvorfor jeg måtte nøjes med nærværende model. Jeg sendte ligeledes billeder af udstillingerne til informanterne, der reagerede positivt og gav udtryk for, at de var stolte over, at de, som de kaldte det, kom ud at rejse sammen med deres forfædre. Særligt den ti siders visuelle portefølje, der blev udgivet i Le Monde i forbindelse med en udstilling i Paris, vakte mange reaktioner fra mine informanter, ligesom udstillingen i Sydney gjorde det. På samme måde som det var tilfældet med vores delvist improviserede fotografiske iscenesættelser i felten, åbnede udstillingerne for en dialog, der gav mig mulighed for at inddrage mine samarbejdspartnere samt publikum i den videnskabelige proces. De samtaler og reaktioner, der voksede ud af udstillingerne, har givet mig nye vinkler på betydningen af Spencer og Gillens oprindelige materiale, mine egne fotografier og materialet fra feltarbejdet. Vinkler, som fortsat informerer min analytiske tilgang, og som har inspireret mit senere relaterede arbejde i Amazonas (2015) og Sibirien (2017).

\section{Konklusion}

I nærværende artikel har jeg redegjort for min metodiske og analytiske praksis $\mathrm{i}$ forbindelse med anvendelsen af fotografiske iscenesættelser som et redskab i antropologisk vidensproduktion. På baggrund af en række empiriske eksempler har jeg argumenteret for, hvorledes intervention og iscenesættelse med udgangspunkt i fotografisk arkivmateriale kan åbne for konstruktivt samarbejde mellem antropolog og informanter. Dette muliggør nye former for kulturkritik forankret i en tilgang, der trækker på inspiration fra både socialvidenskaben og billedkunsten. Jeg har søgt at begrebsliggøre denne metodiske og analytiske praksis med henvisning til begrebet Durcharbeitung for at synliggøre betydningen af den processuelle metodiske og analytiske bearbejdning, jeg kontinuerligt foretager sammen med informanter og kollegaer undervejs i alle projektets faser. Her har jeg især argumenteret for betydningen af en praktisk, kropslig tilgang, der kan komplementere mere konventionelle former for tekstbaseret forskning. Til slut ønsker jeg endnu en gang at foreslå anskuelsen af fotografisk iscenesættelse som en antropologisk genre.

\section{Noter}

1. Tak til mine kollegaer i forskningsgruppen Camera as Cultural Critique på Institut for Kultur og Samfund, Aarhus Universitet, for inspiration, kritik og kommentarer. Mine lokale samarbejdspartnere i det centrale Australien har været en uundværlig kilde til indsigt. Tak til Museum 
Victoria og South Australia Museum for tilladelse til brug af Spencer og Gillens fotografier. Ligeledes tak til de anonyme reviewers for deres gennemlæsning og konstruktive kommentarer.

2. Denne artikel bygger på materiale, der ligeledes diskuteres i en række artikler under udgivelse på engelsk. Alle oversættelser af engelske citater er forfatterens egne.

\section{Litteratur}

Agnew, Vanessa

2004 Introduction. What is Reenactment? Criticism 46(3):327-39.

Bhabha, Homi K.

1994 The Location of Culture. London: Routledge.

Brecht, Bertolt

1964 [1936] Alienation Effects in Chinese Acting. In: J. Willet (ed.): Brecht on Theatre. The Development of an Aesthetic. Pp. 91-120. London: Methuen.

Buckley, Liam

2014 Photography and Photo-Elicitation after Colonialism. Cultural Anthropology 29(4):720-43.

Collingwood, Robin George

1946 The Idea of History. Oxford: Clarendon Press.

Cronin, Paul

2002 Werner Herzog. A Guide for the Perplexed. Conversations with Paul Cronin. London: Faber \& Faber.

Debord, Guy \& Gil J. Wolman

2009 [1956] Directions for the Use of Détournement. In: D. Evans (ed.): Appropriation. Pp. 3539. Cambridge: Whitechapel \& MIT Press.

Deger, Jennifer

2006 Shimmering Screens. Making Media in an Aboriginal Community. Minneapolis: University of Minnesota Press.

2013 In-Between. In: A. Schneider \& C. Wright (eds): Anthropology and Art Practice. Pp. 105-13. London: Bloomsbury.

2016 Thick Photography. Journal of Material Culture 21(1):111-32.

Deleuze, Gilles \& Felix Guattari

$1980 \quad$ Mille Plateaux. Paris: Les éditions de minuit.

Edwards, Elizabeth

2001 Raw Histories. Photographs, Anthropology and Museums. Oxford: Berg.

2008 Photographs, Orality and History. In: E. Edwards \& K. Bhaumili (eds): Visual Sense: A Cultural Reader. Pp. 241-48. Oxford: Berg.

Edwards, Elizabeth (ed.)

1992 Anthropology and Photography. New Haven \& London: Yale University Press.

Gebrauer, Gunter \& Christoph Wulf

1992 Mimesis. Culture, Art, Society. Berkeley: University of California Press. 
Ginsburg, Faye

1995 The Parallax Effect. The Impact of Aboriginal Media on Ethnographic Film. Visual Anthropology Review 11(2):64-76.

2012 Indigenous Counter-Publics. A Foreshortened History. In: Y. McKee \& M. McLagan (eds): Sensible Politics. The Visual Culture of Nongovernmental Activism. Pp. 87-108. New York: Zone Books.

Glaskin, Katie, Myrna Tonkinson, Yasmine Musharbash \& Victoria Burbank (eds)

2008 Mortality, Mourning and Mortuary Practices in Indigenous Australia. Farnham:

Ashgate.

Lydon, Janet

2012 The Flash of Recognition. Photography and the Emergence of Indigenous Rights. Sydney: NewSouth Books.

2014 Calling the Shots. Aboriginal Photographies. Canberra: Aboriginal Studies Press.

Lyotard, Jean-Francois

2004 Anamnesis of the Visible. Theory, Culture \& Society 21(1):107-19.

Marcus, George E. \& Michael M.J. Fischer

1999 Anthropology as Cultural Critique. An Experimental Moment in the Human Sciences (second edition). Chicago: University of Chicago Press.

McCalman, Iain \& Paul A. Pickering

2010 From Realism to the Affective Turn. An Agenda. In: I. McCalman \& P.A.

Pickering (eds): Historical Reenactment. From Realism to the Affective Turn. Pp. 1-17. Hampshire: Palgrave MacMillan.

Michaels, Eric

1993 Bad Aboriginal Art. Tradition, Media and Technology. Minneapolis: University of Minnesota Press.

Mulvaney, John, Howard Morphy \& Allison Petch

1997 My Dear Spencer. The Letters of F.J. Gillen to Baldwin Spencer. Melbourne:

Hylland House.

Musharbash, Yasmine

2008 "Sorry Business is Yapa Way". Warlpiri Mortuary Rituals as Embodied Practice. In: K. Glaskin, M. Tonkinson, Y. Musharbash \& V. Burbank (eds): Mortality, Mourning and Mortuary Practices in Indigenous Australia. Pp. 21-36. Farnham:

Ashgate.

Nichols, Bill

2008 Documentary Reenactment and the Fantasmatic Subject. Critical Inquiry 35:72-89.

Pinney, Christopher \& Nicolas Peterson (eds.)

2003 Photography's Other Histories. Durham: Duke University Press

Prager, Brad

2007 The Cinema of Werner Herzog. Aesthetic Ecstasy and Truth. London: Wallflower Press.

Renov, Michael

2004 The Subject of Documentary. Minneapolis: University of Minnesota Press.

Richard, Veronica M. \& Maria K.E. Lahman 
Said, Edward

1978 Orientalism. New York: Pantheon Books.

Schneider, Arnd \& Christopher Wright (eds)

$2010 \quad$ Between Art and Anthropology. Oxford: Berg.

2013 Anthropology and Art Practice. New York: Bloomsbury Academic.

Taussig, Michael

1993 Mimesis and Alterity. A Particular History of the Senses. New York: Routledge.

Vium, Christian

Under udg. a) Temporal Dialogues. Collaborative Photographic Re-Enactments as a Form of Cultural Critique. Journal of Visual Anthropology. Special issue redigeret af Ton Otto, Peter I. Crawford og Christian Suhr.

Under udg. b) Allegorical Scripts. Visual Note Making, Photo-Elicitation and Photographic Re-Enactments as Collaborative Anthropological Devices. In: A.L. Dalsgaard, C. Rubow, M. Rytter, A. Andersen, M. Nielsen \& M.L. Kusk (eds): Notes on Notes.

2014 Icons of Becoming. Documenting Undocumented Migration from West Africa to Europe. Cahiers d'études africaines LIV, 1-2(213-14):217-40.

\section{Illustrationer}

Figur 1 Registration XP15032. Photograph. Half plate. No glass plate exists. Original print (handwritten annotation): No print. Institution: Museum Victoria. Originalen er genbrugt og overskrevet af Christian Vium i 2014.

Figur 2 Registration AP1045. Francis James Gillen. A young woman of the Warramunga Tribe. Institution: South Australian Museum. Originalen er genbrugt og overskrevet af Christian Vium i 2014.

Figur 3 Registration XP9505. Sir Baldwin Spencer \& Francis J. Gillen. Women wailing during mourning ceremonies, Tennant Creek, Central Australia, 16.-17. august 1901. Institution: Museum Victoria. Originalen er genbrugt og overskrevet af Christian Vium i 2014.

Figur 4 Nola, Roseanne, Marie og Lynette. Amongouna 2014. Christian Vium.

Figur 5 Diptykon. Nola Ross, Amongouna 2014 og Akeyularé, Alice Springs 2014. Christian Vium.

Figur 6 Registration XP9500. Sir Baldwin W. Spencer \& Francis James Gillen. Two widows with cropped hair and covered with white pipe clay sitting under a shelter they built themselves, Tennant Creek, Central Australia, 16.-17. august 1901. Glass plate. Silver gelatin emulsion. Quarter plate. Original glass plate sleeve (handwritten annotation): Death \& Burial. Widows. Warr. Original print (handwritten annotation): No print. Institution: Museum Victoria. Originalen er genbrugt og overskrevet af Christian Vium i 2014.

Figur 7 Installation (detalje). The Wake. Institut Neerlandais. Paris, november 2015. 